\title{
Punicalagin suppresses the proliferation and invasion of cervical cancer cells through inhibition of the $\beta$-catenin pathway
}

\author{
JIANMING TANG, BINGSHU LI, SHASHA HONG, CHENG LIU, JIE MIN, MING HU, YANG LI, \\ YAODAN LIU and LI HONG
}

\begin{abstract}
Department of Gynaecology and Obstetrics, Renmin Hospital of Wuhan University, Wuhan, Hubei 430060, P.R. China
\end{abstract}
Received June 7, 2016; Accepted April 11, 2017

DOI: $10.3892 / \mathrm{mmr} .2017 .6687$

\begin{abstract}
Natural botanical drugs have attracted attention due to their cancer chemopreventive and chemotherapeutic properties in cancer. Punicalagin (PUN) is the major bioactive component of pomegranate peel, and has been shown to have antioxidant, anti-inflammatory, antiviral, antiproliferation and anticancer properties. PUN has been shown to induce apoptosis in several cancer cell lines. The aim of the present study was to investigate the effect of PUN on HeLa human cervical cancer cells in vitro. The viability of the HeLa cells was assessed following treatment with PUN (0, 12.5, 25, 50, 100 and $200 \mu \mathrm{M}$ ) for 24, 36 and $48 \mathrm{~h}$ using a Cell Counting Kit- 8 assay. In addition, the cell cycle distribution, protein expression levels of B-cell lymphoma 2 (Bcl-2)-associated $\mathrm{X}$ protein (Bax), Bcl-2, tissue inhibitor of metalloproteinase (TIMP)-2, TIMP-3 and the $\beta$-catenin pathway, and the activities of matrix metalloproteinase (MMP)-2 and MMP-9 were analyzed following treatment with $\operatorname{PUN}(0,25,50$ and $100 \mu \mathrm{M})$ for $36 \mathrm{~h}$ using cell cycle analysis, western blot analysis and gelatin zymography, respectively. In addition, a wound-healing assay was used to detect cell migration. PUN led to a number of effects on the HeLa cells, including the inhibition of cell proliferation and cell migration, downregulation of MMP-2 and MMP-9, upregulation of TIMP-2 and TIMP-3, cell-cycle arrest in the G1 phase, induction of apoptosis via alterations of Bcl-2 and Bax, and downregulation of $\beta$-catenin and its downstream proteins, cyclin D1 and c-myc. These results suggested that PUN may have chemopreventive and chemotherapeutic effects against cervical cancer in humans through inhibition of the $\beta$-catenin signaling pathway.
\end{abstract}

Correspondence to: Dr Li Hong, Department of Gynaecology and Obstetrics, Renmin Hospital of Wuhan University, 238 Jiefang Road, Wuhan, Hubei 430060, P.R. China

E-mail: drhongli7777@gmail.com

Key words: punicalagin, cervical cancer, $\beta$-catenin, cell cycle, cell migration, apoptosis

\section{Introduction}

Cervical cancer is the third most common type of malignant tumor and the fourth leading cause of cancer-associated mortality among women worldwide (1). Up to $35 \%$ of patients with locally advanced cervical cancer previously treated with surgery or radiation develop persistent, recurrent or metastatic disease, whereas platinum-based chemotherapy represents the gold standard for treatment (2). It is well known that human papilloma virus (HPV) infection is essential in cervical carcinogenesis (3), but HPV infection alone is not sufficient to transform epithelial host cells into cancer cells. Therefore, other factors, including the upregulation of oncogenes and aberrant activation of associated signaling pathways, may be involved in cervical carcinogenesis. A number of previous studies have found that activation of the canonical Wnt/ $\beta$-catenin pathway is necessary and sufficient to induce transformation, and is closely associated with the tumorigenesis and progression of cervical cancer $(1,2,4)$.

Pomegranate (Punica granatum), an ancient fruit known to offer beneficial effects in medicine, is now being recognized as a potential chemopreventive and anticancer agent. Increasing evidence has confirmed the cancer preventive efficacy of pomegranate in vitro and in in vivo animal models, including breast, skin, prostate, lung and colon cancers (5-11). Punicalagin (2,3-hexahydroxydiphenoyl-gallagyl-D-glucose; PUN; Fig. 1) is the major bioactive component of pomegranate peel, and it has been shown to have antioxidant, anti-inflammatory, antiviral, antiproliferation and anticancer properties $(6,12-18)$. PUN has been shown to induce apoptosis in HL-60 human promyelocytic leukemia cells, HT-29 and HCT116 colon cancer lines, Caco- 2 colon adenocarcinoma cells and U87MG glioma cells $(8,18,19)$. Previous investigations have revealed that PUN has effects on various tumor cell lines, including upregulating the expression levels of B-cell lymphoma-2 (Bcl-2)-associated $\mathrm{X}$ protein $(\mathrm{Bax})(7,10), \mathrm{Bcl}-2$-associated death promoter $(10)$, cleaved poly (ADP-ribose) polymerase (PARP) $(7,18,19)$ and cytochrome $c$ (8); promoting the activation of caspase-3 (8) and caspase-9 (18); and downregulating the expression of Bcl-2 $(7,18)$, Bcl-extra large (XL) $(7,8,10)$ and cell cycle proteins, including cyclin $\mathrm{A}(8,18)$, cyclin $\mathrm{B} 1(8,18)$, cyclin $\mathrm{D} 1$, cyclin D2 and cyclin E (7), in addition to regulating the proliferation and apoptosis of cancer cells. 
In the present study, the effect of PUN on HeLa cervical carcinoma cells was investigated. It was demonstrated that PUN induced HeLa cell apoptosis, inhibited the Wnt/ $\beta$-catenin signaling pathway, caused G1/S phase transition arrest and altered the expression of apoptosis-associated proteins. In addition, PUN suppressed the invasion ability of HeLa cells through inhibiting cell migration and altering the protein expression levels of tissue inhibitor of metalloproteinase (TIMP)-2 and TIMP-3, and the activities of matrix metalloproteinase (MMP)-2 and MMP-9.

\section{Materials and methods}

Chemical and reagents. The HeLa cells were obtained from the China Center for Type Culture Collection (Wuhan, China). PUN (>98\% HPLC purity) was purchased from Must Bio-Tech Co., Ltd. (Chengdu, China). A Cell Counting kit-8 (CCK)-8 was purchased from MultiSciences Biotech Co., Ltd. (Hangzhou, China). Dulbecco's modified Eagle's medium (DMEM) and phosphate-buffered saline (PBS) were purchased from Jenom Biotech Co., Ltd. (Hangzhou, China). Trypsin/EDTA solution and fetal bovine serum (FBS) were purchased from Gibco (Thermo Fisher Scientific, Inc., Waltham, MA, USA). The bicinchoninic acid (BCA) protein assay kit and cell cycle analysis kit were purchased from Beyotime Institute of Biotechnology (Suzhou, China). The MMP Gelatin Zymography Assay kit was purchased from Applygen Technologies, Inc. (Beijing, China). Antibodies against $\beta$-catenin (ab32572), c-myc (ab32072), cyclin D1 (ab134175), Bcl-2 (ab59348), Bax (ab32503), $\beta$-actin (ab8227) and TIMP-3 (ab39184) were obtained from Abcam (Cambridge, UK). Antibodies against TIMP-2 (sc21735) was purchased from Santa Cruz Biotechnology, Inc. (Dallas, TX, USA).

Cell culture. The HeLa cells were cultured in DMEM supplemented with heat-inactivated $10 \%$ FBS and $1 \%$ antibiotics (100 IU penicillin and $100 \mu \mathrm{g} / \mathrm{ml}$ streptomycin) in a humidified incubator at $37^{\circ} \mathrm{C}$ and $5 \% \mathrm{CO}_{2}$. Logarithmically growing cells were used in all the subsequent experiments.

Cell viability assay. The cells were seeded into 96-well plates at a density of 5,000 cells/well and incubated for $24 \mathrm{~h}$. The cells were then treated with PUN $(0,12.5,25,50,100$ and $200 \mu \mathrm{M}$ ) for another 24,36 and $48 \mathrm{~h}$ at $37^{\circ} \mathrm{C}$ with $5 \%$ $\mathrm{CO}_{2}$. Following treatment, cell viability was measured using the CCK- 8 method, in which $10 \mu \mathrm{l}$ of CCK- 8 reagent was added and the cells were placed into an incubator at $37^{\circ} \mathrm{C}$ with $5 \% \mathrm{CO}_{2}$ for $\sim 2 \mathrm{~h}$. Finally, the optical density at $450 \mathrm{~nm}$ was detected using a PerkinElmer Victor3 1420 Multilabel Counter (PerkinElmer, Inc., Waltham, MA, USA). Optical density values were employed to represent cell viability.

Cell cycle analysis. The cells were seeded into 6-well plates at a density of $2 \times 10^{5}$ cells/well for $24 \mathrm{~h}$ prior to cell cycle analysis. Following synchronization and treatment for another $36 \mathrm{~h}$ with PUN $(0,25,50$ and $100 \mu \mathrm{M})$, the cells were harvested and then fixed with precooled $70 \%$ ethanol at $4{ }^{\circ} \mathrm{C}$ overnight. The fixed cells were washed with PBS and then stained using the cell cycle analysis kit for $30 \mathrm{~min}$ at $4^{\circ} \mathrm{C}$. The stained cells were determined using a FACSCalibur system (BD Biosciences,
Franklin Lakes, NJ, USA) to examine cell cycle distribution, following which ModFit LT version 4.1 (Verity Software House, Inc., Topsham, ME, USA) was used for data analysis.

Wound healing assay. The HeLa cells were seeded in a 2-cm Petri dish at a concentration of $1 \times 10^{5}$ cells $/ \mathrm{ml}$ and grown overnight. A wound was then made in the cell culture by scratching on the cell layer with a sharp tip, followed by incubation for a further $36 \mathrm{~h}$ with PUN (0 and $50 \mu \mathrm{M})$ in serum-free medium. The gap created by the wound in the treated or untreated cells was then measured under a microscope (CKX31; Olympus Corporation, Tokyo, Japan) to provide an indication of the wound-healing capability of the cells.

MMP gelatin zymography. Following treatment with PUN $(0,25,50$ and $100 \mu \mathrm{M})$ for $36 \mathrm{~h}$, the culture medium was collected. Protein was extracted with RIPA and analyzed using a BCA assay, then mixed with equal volumes of $2 \mathrm{X}$ non-reduced loading buffer and $30 \mu \mathrm{g}$ of total protein was electrophoresed on $10 \%$ SDS-polyacrylamide gels containing $1 \mathrm{mg} / \mathrm{ml}$ gelatin as a protease substrate. The SDS was removed through incubation in $2.5 \%$ Triton $\mathrm{X}-100$ for $30 \mathrm{~min}$, and the gels were incubated in $20 \mathrm{mM}$ glycine ( $\mathrm{pH} 8.3), 10 \mathrm{mM} \mathrm{CaCl}_{2}$ and $1 \mu \mathrm{M} \mathrm{ZnCl}_{2}$ at $37^{\circ} \mathrm{C}$ overnight. The gels were stained with Coomassie Blue to visualize zones of gelatinolytic activity with an Odyssey infrared imaging system (LI-COR Biosciences, Lincoln, NE, USA). Gelatinase-dependent proteolysis was detected as a clear area in a light-blue field. Following scanning of the experiment results; Quantity One graphic analysis software version 4.6.2 (Bio-Rad Laboratories, Inc., Hercules, CA, USA) was used to perform analysis of gray levels on the specific bands.

Western blot analysis. The cells were digested from the plates following treatment with PUN $(0,25,50$ and $100 \mu \mathrm{M})$ for $36 \mathrm{~h}$, following which total protein was extracted from the HeLa cells using RIPA buffer containing PMSF. To measure protein concentrations, a BCA assay kit was used, according to the manufacturer's protocol. Following the addition of protein loading buffer [200 mM of DTT, $40 \mathrm{mM}$ of Tris/HCl, 40\% glycerol, 4\% SDS (pH 6.8) and $0.032 \%$ bromophenol blue] and denaturing at $95^{\circ} \mathrm{C}$ for $5 \mathrm{~min}, 30 \mu \mathrm{g}$ of total protein was separated from the samples by $10 \%$ SDS-polyacrylamide gel electrophoresis and then transferred onto activated PVDF membranes. Following blocking in $5 \%$ skimmed milk at $37^{\circ} \mathrm{C}$ for $1 \mathrm{~h}$, the membranes were blotted with appropriate primary antibodies at $4^{\circ} \mathrm{C}$ overnight, followed by incubation with fluorescence-labeled secondary antibodies (goat anti-mouse/rabbit IRDye700 and IRDye800; C40109-04; 1:10,000; LI-COR Biosciences) for $1 \mathrm{~h}$ at $37^{\circ} \mathrm{C}$. The primary antibodies were as follows: Anti- $\beta$-catenin (1:5,000), anti-c-myc $(1: 10,000)$, anti-cyclin D1 (1:10,000), anti-Bcl-2 (1:200), anti-Bax (1:1,000), anti- $\beta$-actin $(1: 1,000)$, anti-TIMP-2 (1:200) and anti-TIMP-3 $(1: 1,000)$. Signals were detected using an Odyssey infrared imaging system (LI-COR Biosciences).

Statistical analysis. All statistical analyses were performed using SPSS 19.0 (IBM SPSS, Armonk, NY, USA) and data are presented as the mean \pm standard deviation. The data were subjected to one-way analysis of variance. Differences 


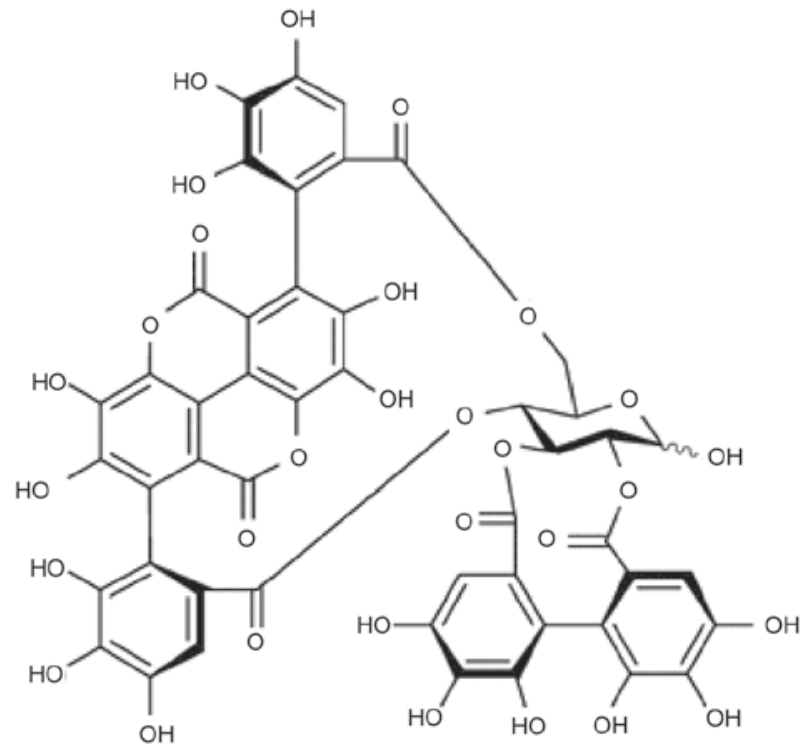

Figure 1. Chemical structure of punicalagin.

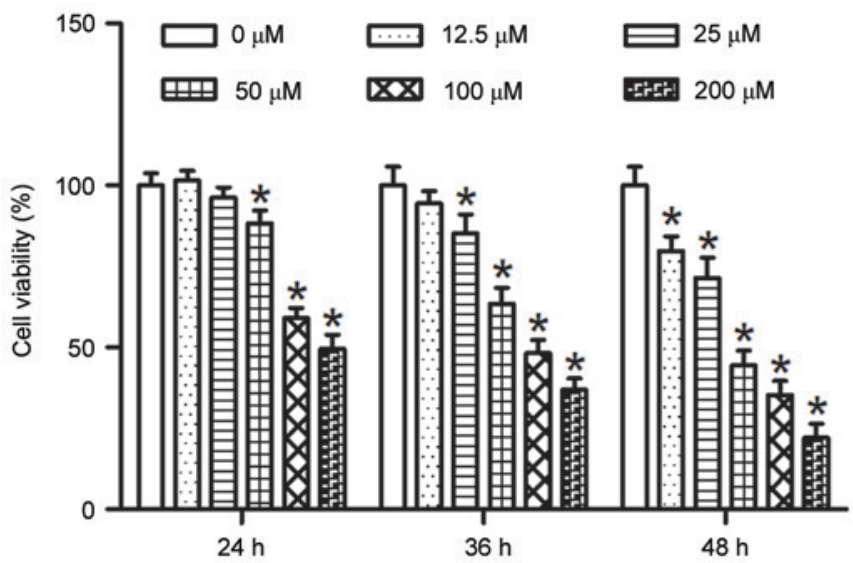

Figure 2. PUN inhibits the viability of HeLa cells in vitro. HeLa cells were treated with increasing concentrations of PUN $(0,12.5,25,50,100$ and $200 \mu \mathrm{M}$ ) for 24,36 and $48 \mathrm{~h}$, and a Cell Counting Kit- 8 assay was used to evaluate cell viability. The number of viable cells was proportional to the absorbance at $450 \mathrm{~nm}$. Treatment with PUN induced a dose- and time-dependent inhibition of cell viability. ${ }^{*} \mathrm{P}<0.05$ vs. $0 \mu \mathrm{M}$ PUN. PUN, punicalagin.

between two groups were determined using Dunnett test, and multiple means were compared using Tukey's test. $\mathrm{P}<0.05$ was considered to indicate a statistically significant difference.

\section{Results}

PUN decreases the viability of HeLa cells. In order to evaluate the effects of PUN on cell growth, HeLa cells were treated with increasing concentrations of PUN $(0,12.5,25,50,100$ and $200 \mu \mathrm{M})$ for various durations (24, 36 and $48 \mathrm{~h}$ ) and the viability of the cells was assessed using CCK- 8 assay. As shown in Fig. 2, following PUN treatment, the viability of the HeLa cells was significantly decreased in a dose- and time-dependent manner.

G1/S phase transition is arrested by PUN in HeLa cells. To further investigate how PUN caused the growth inhibition of
HeLa cells, the cell cycle distribution was analyzed with propidium iodide staining using FACS analysis following treatment with increasing concentrations $(0,25,50$ and $100 \mu \mathrm{M})$ of PUN. As demonstrated in Fig. 3A, the number of cells in the G1 phase increased significantly following PUN treatment for $36 \mathrm{~h}$, compared with the control.

PUN alters the protein expression levels of Bcl2 and Bax in HeLa cells. In order to elucidate the mechanisms underlying the induction of apoptosis by PUN in HeLa cells, mitochondrial features of the intrinsic apoptotic pathway were analyzed. Pro-apoptotic members of the Bcl-2 family, including Bax, are required for the induction of mitochondrial dysfunction during apoptosis. The protein expression levels of Bax and Bcl-2 were assessed using western blot analysis. The results indicated that treatment of the HeLa cells with increasing doses $(0,25$, 50 and $100 \mu \mathrm{M}$ ) of PUN for $36 \mathrm{~h}$ upregulated the expression of Bax and downregulated the expression of anti-apoptotic Bcl-2 (Fig. 3B).

PUN inhibits the progression of HeLa cell migration, and alters the expression of TIMP2 and TIMP-3 and activities of $M M P-2$ and MMP-9. The effects of PUN on the progression of cell migration were evaluated using a wound-healing assay. The size of the region representing the wound site was significantly larger in the cells treated with PUN (50 $\mu \mathrm{M})$, compared with the control (Fig. 4A). This indicated that the untreated cells had higher wound-healing capacity, compared with cells treated with PUN. In addition, the activities of MMP-2 and MMP-9 were higher in the PUN-treated cells, compared with the control group (Fig. 4B), as were the activities of the MMP inhibitors, TIMP-2 and TIMP-3 (Fig. 4C). These results suggested that PUN interfered with the invasion capabilities of the HeLa cells, possibly by disrupting their migration, and altering the expression of MMPs and TIMPs.

Downregulation of the $\beta$-catenin signaling pathway by PUN. Activation of the $\beta$-catenin signaling pathway constitutes an important event in the promotion of cell growth and carcinogenesis of cervical cancer. The present study determined whether PUN affects the expression of $\beta$-catenin in HeLa cells. The HeLa cells were treated with $0,25,50$ and $100 \mu \mathrm{M}$ PUN for $36 \mathrm{~h}$, following which alterations in the levels of $\beta$-catenin and its downstream factors, including cyclin D1 and c-myc, were examined using western blot analysis. As demonstrated in Fig. 5, significant reductions in the expression levels of $\beta$-catenin, cyclin D1 and c-myc were observed in the PUN-treated cells, compared with the untreated cells.

\section{Discussion}

In the present study, it was shown that PUN, a major bioactive component of pomegranate peel, effectively targeted HeLa cervical cancer cells in vitro. Of note, PUN significantly suppressed the proliferative and invasive properties of the HeLa cells. The present study is the first, to the best of the authors' knowledge, to demonstrate the possible molecular mechanisms underlying the effect of PUN on the impairment of cervical cancer cell growth through the $\beta$-catenin signaling pathway. 

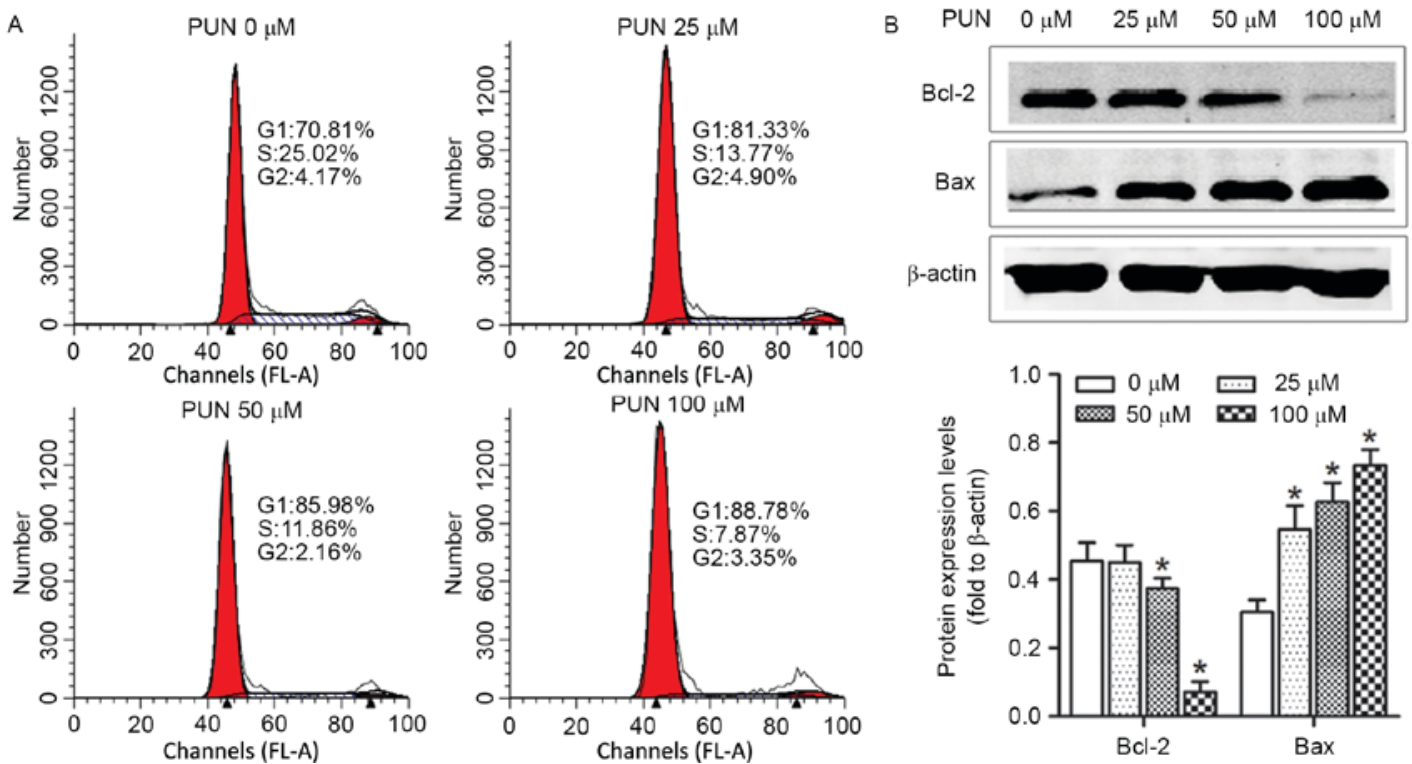

Figure 3. Cell cycle and apoptosis-associated proteins. (A) Cell cycle distribution and (B) changes of apoptosis-associated protein levels in HeLa cells treated with increasing concentrations of PUN $(0,3,6$ and $12 \mu \mathrm{M})$ for $36 \mathrm{~h}$. Each experiment was performed three times and representative data are shown. ${ }^{*} \mathrm{P}<0.05$ vs. $0 \mu \mathrm{M}$ PUN. PUN, punicalagin; Bcl-2, B-cell lymphoma 2; Bax, Bcl-2-associated X protein.

A
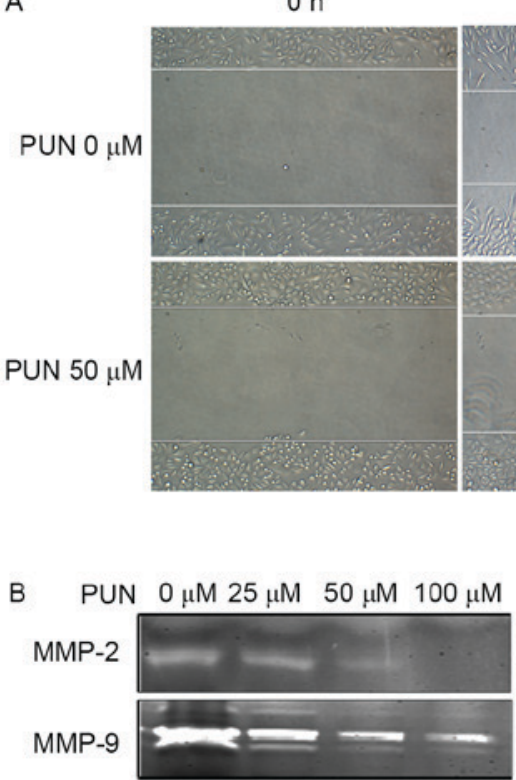

$18 \mathrm{~h}$

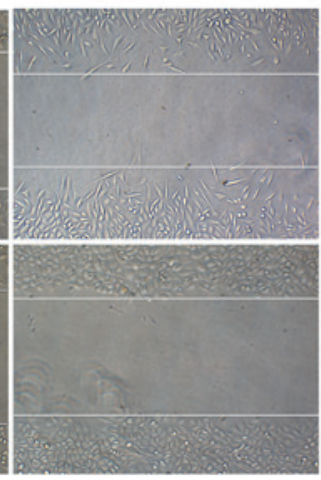

$36 \mathrm{~h}$
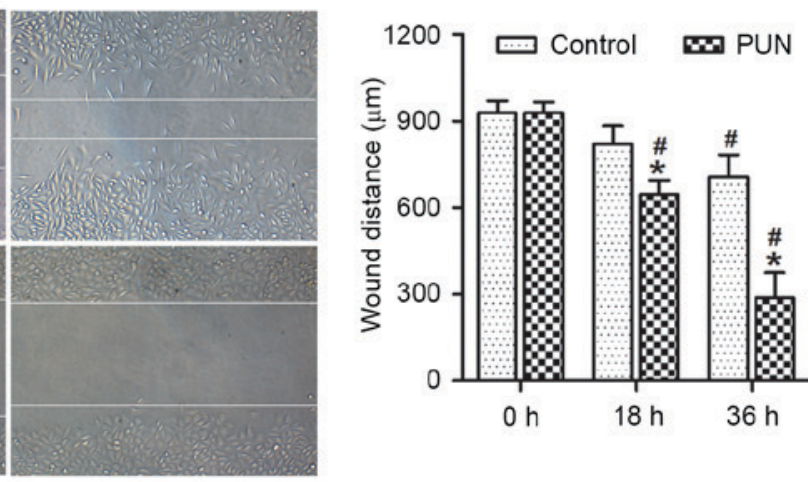

C PUN $0 \mu \mathrm{M} 25 \mu \mathrm{M} \quad 50 \mu \mathrm{M} 100 \mu \mathrm{M}$

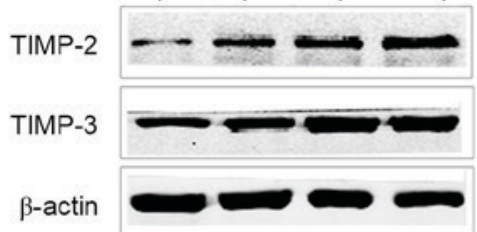

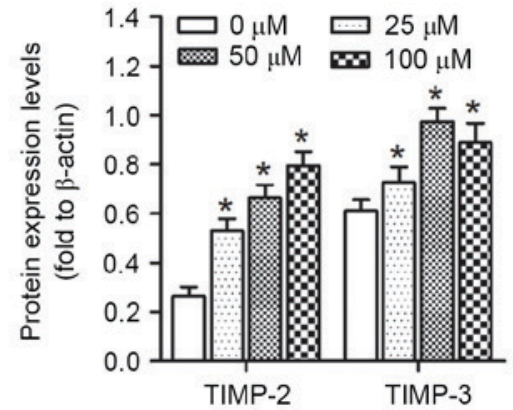

Figure 4. Effect of PUN on cell migration, expression levels of TIMP-2 and TIMP-3, and activities of MMP-2 and MMP-9 in HeLa cells. (A) Wound-healing assay in which a uniform scratch was made in cells cultured in serum-free Dulbecco's modified Eagle's medium for $36 \mathrm{~h}$. Images of the extent of closure were captured at 0 and $36 \mathrm{~h}$ (original magnification, x100). PUN significantly inhibited the migration of HeLa cells. (B) MMP gelatin zymography was used to detect the activities of MMP-2 and MMP-9 in HeLa cells treated with increasing concentrations of PUN $(0,25,50$ and $100 \mu \mathrm{M})$ for $36 \mathrm{~h}$. The results showed that the activities of MMP-2 and MMP-9 were decreased. (C) Expression levels of TIMP-2 and TIMP-3 were analyzed using western blot analysis in HeLa cells following treatment with PUN $(0,25,50$ and $100 \mu \mathrm{M})$. TIMP-2 and TIMP-3 were downregulated following treatment with PUN. Each experiment was performed three times and representative data are shown. ${ }^{*} \mathrm{P}<0.05$ vs. $0 \mu \mathrm{M}$ PUN and ${ }^{~} \mathrm{P}<0.05$ vs. 0 h. PUN, punicalagin; MMP, matrix metalloproteinase; TIMP, tissue inhibitor of metalloproteinase.

PUN inhibited the proliferation of HeLa cells in a dose- and time-dependent manner in the present study. Previous studies have reported the anti-proliferation and pro-apoptotic effects of PUN in several cancer cell lines through alterations in the 

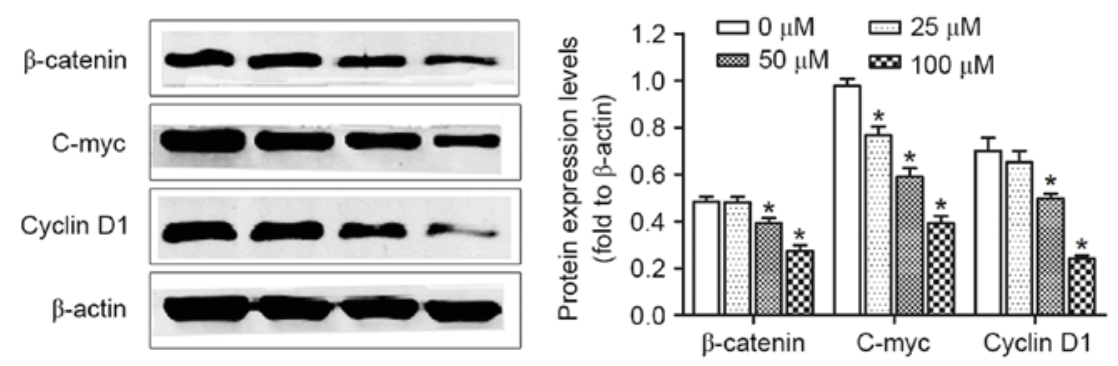

Figure 5. Alterations in $\beta$-catenin signaling-associated proteins. HeLa cells treated with increasing concentrations of PUN $(0,25,50$ and $100 \mu \mathrm{M})$ for $36 \mathrm{~h}$ and alterations of $\beta$-catenin signaling-associated proteins were analyzed. Each experiment was performed three times, and representative data are shown. ${ }^{*} \mathrm{P}<0.05$ vs. $0 \mu \mathrm{M}$ PUN. PUN, punicalagin.

expression of apoptosis-associated proteins and cell cycle arrest $(5,7-9,11,16,18,20)$. Pomegranate fruit extract (PFE) has been reported to upregulate the protein levels of pro-apoptotic Bax and Bcl2-antagonist/killer 1 (Bak), and downregulate the protein levels of anti-apoptotic Bcl-XL and Bcl-2 in human prostate cancer PC3 cells $(7,11)$. PUN decreases the expression of Bcl-2, and increases the expression levels of activated caspase-9 and PARP in human U87MG glioma cells (18). Similarly, PUN induces apoptosis in human colon cancer cells via the intrinsic pathway, with release of cytochrome $c$ into the cytosol, activation of caspase- 9 and caspase-3, and downregulation of Bcl-XL (8). In the present study, PUN significantly decreased the protein expression of anti-apoptotic Bax and increased the protein expression of pro-apoptotic $\mathrm{Bcl}-2$ in the HeLa cells. PFE has also been shown to decrease the expression of cyclins D1, D2 and E, and cyclin-dependent kinase (cdk)2, cdk4 and cdk6 in PC3 human prostate cancer cells and A549 human lung cancer cells, with cell cycle arrest at the G1 phase $(7,9)$. By contrast, PUN downregulate cyclin A and B1, and upregulates cyclin E in Caco-2 human colon adenocarcinoma cells, with cell-cycle arrest at the $\mathrm{S}$ phase (8). In U87MG human glioma cells, PUN induces the upregulation of cyclin $\mathrm{E}$ and the downregulation of cyclin $\mathrm{A}$ and $\mathrm{B}$, with cell cycle arrest at the G2/M phase (18). In the present study, PUN inhibited the $\beta$-catenin signaling pathway and decreased the expression of cyclin D1. Cyclin D1 is essential in the phosphorylation of retinoblastoma and its release from E2 Transcription Factor, which results in progression of the cell cycle and cellular proliferation. The cell cycle distribution assay showed that the PUN-treated HeLa cells were arrested at the G1 phase. These contrasting results indicated that PUN may have different effects on cell cycle progression in different cancer cells.

Several epigenetic and genetic factors significantly affect the genesis and development of cancer. Previous studies $(9,16)$ on A549 lung cancer cells revealed the inhibition of mitogen-activated protein kinase, phosphoinositide 3-kinase/AKT and nuclear factor (NF) $-\kappa \mathrm{B} / \mathrm{p} 65$ signaling, in addition to downregulation of the protein levels of $\mathrm{Ki}-67$ and proliferating cell nuclear antigen, by PUN. In addition, PUN has been shown to increase the phosphorylation of 5' AMP-activated protein kinase and $\mathrm{p} 27^{\mathrm{T} 198}$, and then induce autophagic cell death of U87MG cells (18). There is evidence that pomegranate juice significantly suppresses the TNF $\alpha$-induced protein expression of cyclooxygenase 2, binding of $\mathrm{NF}-\kappa \mathrm{B}$ and activation of AKT in several cancer cell lines (16). In addition to these signaling pathways, the Wnt/ $\beta$-catenin pathway also contributes to tumorigenesis and progression. Substantial investigation has revealed that the $\mathrm{Wnt} / \beta$-catenin pathway is associated with cervical cancer $(1,2,4)$, specifically in chemoresistance and possesses potential as a target for chemosensitization. Wnt/ $\beta$-catenin target genes, including cyclin D1, c-myc and survivin, regulate cell proliferation and apoptosis, thereby mediating cancer initiation and progression. Wnt/ $\beta$-catenin target genes can be divided into a stemness/proliferation group, which is active early in tumor progression, and an epithelial-mesenchymal transition/dissemination group, which is expressed in late-stage tumors (21). The Wnt/ $\beta$-catenin pathway has been shown to be a therapeutic molecular target for cervical cancer. In the present study, it was found that PUN decreased the expression of $\beta$-catenin and its downstream proteins, including cyclin D1 and c-myc, which are essential factors of cancer cell growth and proliferation.

PFE has been reported to inhibit UV-mediated expression of MMPs and decrease of TIMP-1, attenuate UV-induced oxidative stress, and inhibit the stress-induced molecular pathways associated with a high risk of carcinogenesis in EpiDerm $^{\mathrm{TM}}$ (reconstituted human skin) $(6,10,22)$. Several studies have demonstrated the key involvement of MMPs in tumor invasion and metastases (23-25). Therefore, PUN may have functions in inhibiting tumor cell invasion. In the present study, PUN significantly inhibited the migration of HeLa cells when treated for $24 \mathrm{~h}$. In addition, the activities of MMP-2 and MMP-9 were decreased and the protein expression levels of TIMP-2 and TIMP-3 were increased following treatment with PUN.

In addition to the above roles, there have been a number of studies on PUN and its antimicrobial activities against bacteria, including Salmonella, Escherichia coli and Vibrio cholerae, and viruses, including hepatitis $\mathrm{C}$ virus, human immunodeficiency virus, H1N1 and human cytomegalovirus, with mechanisms of actions including $\mathrm{pH}$-independent bacterial and viral growth inhibition, reductions in viral infectivity and binding to host cell receptors, and structural damage to viruses $(14,26)$. Therefore, in addition to its antitumor effect, it was hypothesized that PUN may have an anti-HPV effect, although this has not been investigated.

In conclusion, the present study identified a novel activity for PUN in HeLa human cervical cancer cells, namely, the ability to induce the suppression of proliferation, cell cycle arrest and inhibition of invasion. Therefore, PUN may be useful in the development of adjuvant therapies to treat cervical cancer. 


\section{Acknowledgements}

The authors would like to thanks all the teachers in the Department of Gynecology and Obstetrics and Central Laboratory, Renmin Hospital of Wuhan University, for their technical assistance.

\section{References}

1. Liao CJ, Wu TI, Huang YH, Chang TC, Lai CH, Jung SM, Hsueh $\mathrm{C}$ and Lin KH: Glucose-regulated protein 58 modulates $\beta$-catenin protein stability in a cervical adenocarcinoma cell line. BMC Cancer 14: 555, 2014.

2. Li F, Wang T and Tang S: SOX14 promotes proliferation and invasion of cervical cancer cells through $\mathrm{Wnt} / \beta$-catenin pathway. Int J Clin Exp Pathol 8: 1698-1704, 2015.

3. Ljubojevic S and Skerlev M: HPV-associated diseases. Clin Dermatol 32: 227-234, 2014.

4. Li H, Jiao S, Li X, Banu H, Hamal S and Wang X: Therapeutic effects of antibiotic drug tigecycline against cervical squamous cell carcinoma by inhibiting Wnt/ $\beta$-catenin signaling. Biochem Biophys Res Commun 467: 14-20, 2015.

5. Mehta R and Lansky EP: Breast cancer chemopreventive properties of pomegranate (Punica granatum) fruit extracts in a mouse mammary organ culture. Eur J Cancer Prev 13: 345-348, 2004.

6. Aslam MN, Lansky EP and Varani J: Pomegranate as a cosmeceutical source: Pomegranate fractions promote proliferation and procollagen synthesis and inhibit matrix metalloproteinase-1 production in human skin cells. J Ethnopharmacol 103: 311-318, 2006.

7. Malik A, Afaq F, Sarfaraz S, Adhami VM, Syed DN and Mukhtar H: Pomegranate fruit juice for chemoprevention and chemotherapy of prostate cancer. Proc Natl Acad Sci USA 102: 14813-14818, 2005.

8. Larrosa M, Tomás-Barberán FA and Espín JC: The dietary hydrolysable tannin punicalagin releases ellagic acid that induces apoptosis in human colon adenocarcinoma Caco-2 cells by using the mitochondrial pathway. J Nutr Biochem 17: 611-625, 2006.

9. Khan N, Hadi N, Afaq F, Syed DN, Kweon MH and Mukhtar H: Pomegranate fruit extract inhibits prosurvival pathways in human A549 lung carcinoma cells and tumor growth in athymic nude mice. Carcinogenesis 28: 163-173, 2007.

10. Syed DN, Malik A, Hadi N, Sarfaraz S, Afaq F and Mukhtar H: Photochemopreventive effect of pomegranate fruil extract on UVA-mediated activation of cellular pathways in normal human epidermal keratinocytes. Photochem Photobiol 82: 398-405, 2006.

11. Malik A and Mukhtar H: Prostate cancer prevention through pomegranate fruit. Cell Cycle 5: 371-373, 2006.

12. Aqil F, Munagala R, Vadhanam MV, Kausar H, Jeyabalan J, Schultz DJ and Gupta RC: Anti-proliferative activity and protection against oxidative DNA damage by punicalagin isolated from pomegranate husk. Food Res Int 49: 345-353, 2012.
13. Jean-Gilles D, Li L, Vaidyanathan VG, King R, Cho B, Worthen DR, Chichester CO III and Seeram NP: Inhibitory effects of polyphenol punicalagin on type-II collagen degradation in vitro and inflammation in vivo. Chem Biol Interact 205: 90-99, 2013.

14. Li G, Feng Y, Xu Y, Wu Q, Han Q, Liang X, Yang B, Wang X and $\mathrm{Xia} X$ : The anti-infective activity of punicalagin against Salmonella enterica subsp. enterica serovar typhimurium in mice. Food Funct 6: 2357-2364, 2015.

15. Seeram NP, Adams LS, Henning SM, Niu Y, Zhang Y, Nair MG and Heber D: In vitro antiproliferative, apoptotic and antioxidant activities of punicalagin, ellagic acid and a total pomegranate tannin extract are enhanced in combination with other polyphenols as found in pomegranate juice. J Nutr Biochem 16: 360-367, 2005.

16. Syed DN, Afaq F and Mukhtar H: Pomegranate derived products for cancer chemoprevention. Semin Cancer Biol 17: 377-385, 2007.

17. Xu X, Li H, Hou X, Li D, He S, Wan C, Yin P, Liu M, Liu F and $\mathrm{Xu}$ J: Punicalagin Induces Nrf2/HO-1 Expression via upregulation of PI3K/AKT pathway and inhibits LPS-induced oxidative stress in RAW264.7 macrophages. Mediators Inflamm 2015: 380218, 2015.

18. Wang SG, Huang MH, Li JH, Lai FI, Lee HM and Hsu YN: Punicalagin induces apoptotic and autophagic cell death in human U87MG glioma cells. Acta Pharmacol Sin 34: 1411-1419, 2013.

19. Chen LG, Huang WT, Lee LT and Wang CC: Ellagitannins from Terminalia calamansanai induced apoptosis in HL-60 cells. Toxicol In Vitro 23: 603-609, 2009.

20. Lansky EP and Newman RA: Punica granatum (pomegranate) and its potential for prevention and treatment of inflammation and cancer. J Ethnopharmacol 109: 177-206, 2007.

21. Arend RC, Londoño-Joshi AI, Straughn JM Jr and Buchsbaum DJ: The Wnt $/ \beta$-catenin pathway in ovarian cancer: A review. Gynecol Oncol 131: 772-779, 2013.

22. Afaq F, Zaid MA, Khan N, Dreher M and Mukhtar H: Protective effect of pomegranate-derived products on UVB-mediated damage in human reconstituted skin. Exp Dermatol 18: 553-561, 2009.

23. Aroui S, Najlaoui F, Chtourou Y, Meunier AC, Laajimi A, Kenani $\mathrm{A}$ and Fetoui $\mathrm{H}$ : Naringin inhibits the invasion and migration of human glioblastoma cell via downregulation of MMP-2 and MMP-9 expression and inactivation of p38 signaling pathway. Tumour Biol 37: 3831-3839, 2016.

24. Hussain A, Harish G, Prabhu SA, Mohsin J, Khan MA, Rizvi TA and Sharma C: Inhibitory effect of genistein on the invasive potential of human cervical cancer cells via modulation of matrix metalloproteinase- 9 and tissue inhibitiors of matrix metalloproteinase-1 expression. Cancer Epidemiol 36: e387-e393, 2012.

25. Lu H, Cao X, Zhang H, Sun G, Fan G, Chen L and Wang S: Imbalance between MMP-2, 9 and TIMP-1 promote the invasion and metastasis of renal cell carcinoma via SKP2 signaling pathways. Tumour Biol 35: 9807-9813, 2014.

26. Howell AB and D'Souza DH: The pomegranate: Effects on bacteria and viruses that influence human health. Evid Based Complement Alternat Med 2013: 606212, 2013. 